Revista Oficial del Poder Judicial

ÓRGANO DE INVESTIGACIÓN DE LA CORTE SUPREMA DE JUSTICIA DE LA REPÚBLICA DEL PERÚ

Vol. 13, n. ${ }^{\circ} 16$, julio-diciembre, 2021, 243-268

ISSN: 1997-6682 (Impreso)

ISSN: 2663-9130 (En Línea)

DOI: 10.35292/ropj.u13i16.465

\title{
Ricardo Palma: tres tradiciones y algunas reflexiones sobre la justicia, el derecho y la literatura
}

\section{Ricardo Palma: three traditions and some reflections on justice, law, and literature 0 (아}

FRANCISCO TÁVARA CÓRDOVA

Universidad Ricardo Palma

(Lima, Perú)

Contacto: francisco.tauara@urp.edu.pe

https://orcid.org/0000-0002-5258-4058

GLADYS FLORES HEREDIA

Universidad Ricardo Palma

(Lima, Perú)

Contacto: gladys.floresh@urp.edu.pe

https://orcid.org/0000-0001-7515-6905

\section{RESUMEN}

El artículo centra su atención en tres tradiciones de Ricardo Palma Soriano (1833-1919), que se encuentran en su obra Tradiciones peruanas: «iA la cárcel todo Cristo!», «El corregidor de Tinta» $\mathrm{y}$ «Justos y pecadores». Se examina cómo, en estas tradiciones, el autor introduce algunas reflexiones sobre la justicia. En específico, 
se explican sus ideas a propósito de la igualdad ante la ley, la justicia como práctica de violencia y la necesidad de contar con principios reflexivos y técnicos para que los agentes de justicia realicen objetivamente su labor. Esta aproximación tiene implícita la preocupación metodológica del derecho y la literatura. Por ello, se toma el texto literario para explicar sus potencialidades reflexivas en torno a la justicia. Así, en la explicación se emplearán categorías de la historia, el derecho y la literatura.

Palabras clave: Ricardo Palma; Tradiciones peruanas; derecho; literatura; justicia.

\section{ABSTRACT}

The article is focused on three traditions of Ricardo Palma Soriano (1833-1919), found in his work Tradiciones peruanas: «A la cárcel todo Cristo!», «El corregidor de Tinta» and «Justos y pecadores». It examines how, in these traditions, the author introduces some reflections on justice. Specifically, it explains his ideas about equality before the law, that is, the justice as a practice of violence and the need for reflective and technical principles for the actors of justice to carry out their work objectively. This approach has an implicit methodological concern with law and literature. Therefore, the literary text is taken to explain its reflective potentialities about justice. Thus, categories of history, law, and literature will be used in the explanation.

Key words: Ricardo Palma; Tradiciones peruanas; law; literature; justice.

Recibido: 01/09/2021 Aceptado: 08/10/2021 


\section{INTRODUCCIÓN}

Los escritores (poetas, narradores y dramaturgos) proponen en sus obras, a veces, sin pretenderlo, un valioso mundo de interacciones sociales donde sus personajes formulan reflexiones iusfilosóficas movidos por el deseo de justicia. Por ello, podemos decir que la literatura es un escenario privilegiado para reflexionar y evaluar múltiples percepciones históricas o actuales sobre la sociedad, sus instituciones y los problemas que las aquejan. Tópicos como la pobreza, la migración, la marginalidad, el racismo, la discriminación, la contaminación ambiental, el fundamentalismo, la corrupción, la injusticia y otras cuestiones de órdenes intercultural e inclusivo son abordados en las obras literarias que crean los diversos escritores. De hecho, asumimos que «la Literatura plantea los grandes temas del Derecho sin tecnicismos profesionales» (Trazegnies, 2011, p. 27), sin que ello suponga mermar su utilidad reflexiva, pues los textos son como «testimonios literarios» cargados de significación sobre el sistema jurídico (Pásara, 1982, pp. 19-20). Incluso podríamos agregar que algunos de los autores se han formado en el campo académico del derecho y, desde esa arena, construyeron sus historias, sus personajes y sus ambientes. Ciñéndonos al caso peruano, podríamos mencionar a los escritores que tuvieron una formación en el mundo de las leyes. Estos son Enrique López Albújar (1872-1966), César Abraham Vallejo Mendoza (1892-1938), Ricardo Peña Barrenechea (1896-1939), Julio Ramón Ribeyro (1929-1994), Mario Vargas Llosa (1936) y Alfredo Bryce Echenique (1939). Entiéndase que no proponemos vincular mecánicamente la formación académica del autor con lo que ocurre en el mundo que construyen en sus obras. Ofrecemos, más bien, una reflexión que permita advertir la densidad conceptual que se concentra como metáfora en algunos textos. Así, podríamos comprender las reflexiones sobre las limitaciones de la administración de justicia que plantea Vallejo en su libro de relatos Escalas (1923); o comprenderíamos también el llamado por recuperar la memoria histórica 
para que la institución judicial recuerde sus valores humanos, llamado que realiza Vargas Llosa en la novela El sueño del celta (2010), donde vemos representado al juez titular en la Corte de Iquitos, Carlos A. Valcárcel (1881), a quien el narrador llama «juez estrella» por su valiente, humana y profesional tarea de defender la integridad y la vida de nuestros hermanos nativos en la Amazonía peruana, que estaban siendo aniquilados por la transnacional del empresario Julio César Arana.

Don Ricardo Palma Soriano (1833-1919) también se formó en jurisprudencia, y lo hizo en el Real Convictorio de San Carlos, a donde ingresó antes de cumplir los diecisiete años y abandonó a los veinte (1849-1853). El lapso fue suficiente para conocer los fundamentos de la jurisprudencia y para sumarle al espíritu y la historia de las leyes su interés por temas literarios, políticos, liberales y anticlericales. De hecho, cuando se repasa el listado de materias que para la época se impartían en San Carlos, encontraremos, ordenándolos con un criterio actual, los siguientes idiomas: el latín, el inglés y el francés. Por el campo de la literatura, asignaturas como Literatura Española y Literatura Latina. También en el área de humanidades, Palma llevó cursos de Economía Política, Ética, Religión, Psicología del Pensamiento, Derecho Canónico, Derecho Civil, Derecho Constitucional y de Gentes y Derecho Natural; estos se combinaron con materias como Mecánica de Fluidos, Astronomía, Óptica, Geometría, Geografía e Historia. Es decir:

Palma escogió para su formación académica algunos de estos cursos, siendo la literatura y la historia los que más lograron llamar su atención. Sin embargo, no por ello dejó de descuidarse en el aprendizaje de los demás cursos, llegando a estudiar algunas materias pertenecientes al área de la jurisprudencia y de la filosofía. Al parecer, el joven estudiante llegó a mostrar interés en algunos cursos, tales como el derecho natural, derecho canónico, derecho constitucional, religión, fundamentos del catolicismo y dogmas principales, ya que, en muchas de sus obras, escritos y cartas, el tradicionista 
llegó a hacer mención de varios autores y libros pertenecientes a dichas materias, lo cual es una señal evidente del conocimiento de esos cursos (Pérez, 2015, p. 52; las cursivas son nuestras).

La referencia que acabamos de realizar informa sobre la inclinación de Palma hacia la historia y la literatura, pero también precisa el amplio campo de conocimientos que recibió en su breve formación académica. Sin ánimos de exhortar el ejercicio de una lógica reflexiva mecanicista o determinista, tengamos en cuenta este hecho de la experiencia de la formación del conocimiento, pues examinaremos la manifestación de algunas ideas sobre el campo de la administración de justicia que Palma realiza en sus tradiciones. Nuestra atención estará centrada en tres textos: «iA la cárcel todo Cristo!», «El corregidor de Tinta» y «Justos y pecadores». Explicaremos cómo en estas tradiciones Palma propone algunas reflexiones sobre la igualdad ante la ley, el equilibrio y la desmesura de la justicia y los peligros de una falta de formación reflexivo-técnico-afectiva de los administradores de la justicia. A continuación, presentamos cada uno de estos tópicos en tres momentos.

\section{2. «¡A LA CÁRCEL TODO CRISTO!»O LA REFLEXIÓN SOBRE LA IGUALDAD ANTE LA LEY}

Las tradiciones de Palma son piezas literarias donde confluyen y se mezclan lo histórico y lo ficcional, así también elementos de las crónicas, el cuento, la leyenda y los datos históricos. Los especialistas en el estudio de las obras de Palma, los llamados "palmistas», distinguen, aunque no esquemáticamente, tres componentes en las tradiciones: el parrafillo histórico, el hecho anecdótico y el desenlace con moraleja o conseja (véase Cornejo, 1998, p. 147). Estamos de acuerdo con ello, pero consideramos necesario agregar a estos componentes uno de orden temático, bastante visible en algunas tradiciones. Nos referimos al elemento reflexivo jurídico. La tradición «¡A la cárcel todo Cristo!», que forma parte de la segunda 
serie de los textos de Palma, y que se publicó en 1874, ofrece una imagen nítida del paisaje urbano y, con ella, visibiliza también los problemas sociales del sistema jurídico colonial y la implementación de normas jurídicas que procuran establecer la paz social. Escribe Palma (2014):

Grande era la desmoralización de Lima cuando O'Higgins entró a ejercer el mando. Según el censo mandado formar por el virreybailío Gil y Lemus, contaba la ciudad en el recinto de sus murallas 52627 habitantes, y para tan reducida población excedía de mil el número de carruajes particulares que, con ricos arneses y soberbios troncos, se ostentaban en el paseo de la Alameda. Tal exceso de lujo basta a revelarnos que la moralidad social no podía rayar muy alto.

Los robos, asesinatos y otros escándalos nocturnos se multiplicaban, y para remediarlos juzgó oportuno su excelencia promulgar bandos, previniendo que sería aposentado en la cárcel todo el que después de las diez de la noche fuese encontrado en la calle por las comisiones de ronda. Las compañías de encapados o agentes de policía, establecidas por el virrey Amat, recibieron aumento y mejora en el personal con el nombramiento de capitanes, que recayó en personas notables.

Pero los bandos se quedaban escritos en las esquinas y los desórdenes no disminuían. Precisamente los jóvenes de la nobleza colonial hacían gala de ser los primeros infractores. El pueblo tomaba ejemplo en ellos y viendo el virrey que no había forma de extirpar el mal, llamó un día a los cinco capitanes de las compañías de encapados (pp. 209-210; salvo «encapados», las cursivas son nuestras).

Este fragmento es muy claro al presentar a los actores sociales e históricos de la época: por un lado, tenemos al virrey Ambrosio Bernardo O'Higgins, quien promulga la normativa de conducta, con carácter coercitivo, para organizar la vida en sociedad; es decir, mediante los «bandos» se propone restringir el libre tránsito de las personas luego de las diez de la noche. Recordemos que, según 
los documentos legales de la administración jurídica colonial, el bando era un mandato oficial cuya finalidad consistía en imponer órdenes que regulen las actividades cotidianas de la vida en las ciudades. La difundía un pregonero por encargo de un superior (autoridad militar o política, como el alcalde). Aquel replicaba oralmente el documento legal por diferentes plazas y espacios de confluencia social, y procedía a pegarlos en las paredes para una mayor recordación y difusión entre los pobladores de la urbe (Castro, 2016, pp. 17-20). El bando se constituía, junto con los autos acordados en las audiencias y las ordenanzas de los cabildos, en una de las tres formas escritas de concreción jurídica propiamente americana, esto es, propio del derecho penal indiano (véase Ávila, 1946, p. 19). En el caso del segmento de la tradición palmiana, el bando busca poner fin a «los robos, asesinatos y otros escándalos nocturnos». Pero no se trata solo de ofrecer el cuadro de una dinámica social. En la cita se puede percibir cómo Palma presenta y regula la intensidad de los hechos delictivos que atentan, primero, contra la propiedad privada; segundo, la vida; $y$, tercero, la tranquilidad social. Esta gradación, pensamos, no es casual, pues la promulgación del disuasivo legal no acontece de buenas a primeras, sino tras una serie de prácticas delictivas in crescendo.

Agreguemos que no es la única tradición en la que Palma introduce su reflexión sobre los usos y abusos de este dispositivo legal. «Pepe bandos. Apuntes sobre el virrey marqués de Castelfuerte», por ejemplo, presenta también un cuadro de la aplicación extrema del bando. Precisamente para mantener a raya el descontento social sobre la condena a muerte de José de Antequera, para reprimir cualquier acción que contravenga la orden de muerte por horca, Palma (2014) informa que el virrey «hizo publicar [...] un bando terrorífico, imponiendo pena de muerte a los que intentasen detener en su camino a la justicia humana» (p. 423; las cursivas son nuestras). Hemos colocado en cursivas el calificativo con el que Palma hace 
acompañar la normativa. Con ello, destacamos lo que el propio tradicionista advierte: la desmesura de la normativa y el exceso punitivo. Seguidamente, y en la línea de ejercer la crítica a través de la ironía, Palma (2014) acopia en un párrafo enumerativo una variada cantidad de bandos con el propósito de que pierdan importancia y se haga evidente la arbitrariedad indiscriminada:

Bandos contra las mujeres que, llamándose honestas, se presentan en público luciendo cosas que no siempre son para lúcidas; bandos contras los ermitaños de Baco; bandos contra el libertinaje de las costumbres; bandos sobre el salario; bandos sobre los monederos falsos; bandos enumerando los festejos con que debía celebrarse la canonización de San Francisco Solano, y tanta era su fiebre de promulgar bandos que, como hemos dicho, el pueblo limeño lo llamaba Pepe bandos (p. 426; las cursivas son nuestras).

Volvamos al pasaje de «¡A la cárcel todo Cristo!». En el referido fragmento se muestra una reflexión sobre el funcionamiento de las normas que regulan la vida en sociedad, pues en sus imágenes identificamos el organigrama que distribuye funciones y responsabilidades. En efecto, se visualiza a quienes tendrán el trabajo de hacer cumplir la proclama: las «compañías de encapados o agentes de policía», quienes conducirán a la «cárcel» a todos los que se atrevan a transgredir la norma. La reflexión jurídica sobre las funciones y los dispositivos de control social es bastante clara: sirven para vigilar, reprimir y castigar. Ahora bien, los principales infractores, según el tradicionista, eran los «jóvenes de la nobleza colonial», y quien imitaba la errada actitud era el «pueblo». Por ello, se dispone de los instrumentos legítimos («bandos», «agentes de policía» y «cárcel»). El lector podrá observar que el fragmento de la tradición presenta a los principales elementos del sistema jurídico colonial, y no para contemplar el correcto funcionamiento, sino para ofrecer una imagen del problema del desacato de una normativa y la repercusión que tiene: su fracaso como dispositivo de control 
social. Incluso se sugiere que la prohibición es letra muerta, pues quienes deben acatarla no lo hacen. Para cuestionar más esta falta, se recrea el diálogo entre la autoridad y los agentes que deben hacer cumplir la norma:

—Tengo noticias, señores — les dijo-, que ustedes llevan a la cárcel solo a los pobres diablos que no tienen padrino que les valga; pero que cuando se trata de uno de los marquesitos o condesitos que andan escandalizando el vecindario con escalamientos, serenatas, estocadas y jolgorios, vienen las contemporizaciones y se hacen ustedes de la vista gorda. Yo quiero que la justicia no tenga dos pesos $y$ dos medidas, sino que sea igual para grandes y chicos. Ténganlo ustedes así por entendido, y después de las diez de la noche... ¡a la cárcel todo Cristo! (Palma, 2014, p. 210; las cursivas son nuestras).

El fragmento citado revela por qué no resulta efectiva la normativa para el restablecimiento del orden social urbano colonial. Resulta probable que se trate de uno de los momentos donde tempranamente se ilustra la inconexión entre la reglamentación judicial y la práctica policial frente a la desobediencia social. Así, se devela que el fracaso de la norma se debe a que los agentes de la policía no sancionan a los infractores de la aristocracia. El hecho pone en evidencia el funcionamiento de la estructura jurídica colonial, una donde rigen los privilegios. Y ello no es novedad en materia jurídica, ya que incluso tras el establecimiento de la República, la «independencia política» no necesariamente supuso la conquista de la «independencia legal», «pues durante muchos años continuó rigiendo la ley española, en cuanto no fuese contraria a los dispositivos dictados por el gobierno independiente» (Ramos, 2019, p. 47; las cursivas son nuestras).

La tradición de Palma, entre la ironía y el detalle histórico, critica que no se aplica ni respeta el principio de igualdad ante la ley. El brazo que debe hacer cumplir la norma no la ejecuta con estricta dureza e imparcialidad. Por esa razón, aunque el sistema 
jurídico colonial se presente a modo jerárquico, dispuesto mediante funciones, no es efectivo por falta de competencia de uno de los agentes y porque estructuralmente no se han quebrantado las prerrogativas coloniales. Por ello, las palabras del virrey exigen, de manera irónica y paradójica, la igualdad ante la ley y la eliminación de privilegios: "Yo quiero que la justicia no tenga dos pesos y dos medidas, sino que sea igual para grandes y chicos» (Palma, 2014, p. 210).

El curso de la historia que presenta esta tradición termina con dos hechos encadenados y significativos: en el primero, el virrey sanciona a los agentes que permiten transitar a los «grandes» después de la hora señalada (es decir, penaliza a quienes pasaban por alto las transgresiones de los aristócratas), y, en el segundo, se hace de público conocimiento que uno de los agentes arresta al virrey por infringir la ordenanza de inmovilidad. Una y otra acción, la condescendencia y la inflexibilidad, son momentos extremos que Palma distribuye de este modo, pues quiere convencernos de que si cada uno de los agentes que intervienen en la administración de justicia no cumple con la función que se le encomienda, es seguro que la normativa legal caerá en saco roto, es decir, no servirá para promover la convivencia en sociedad.

Con esta tradición, Palma revela que la efectividad de una norma requiere, por un lado, que su establecimiento esté guiado por criterios de equilibrio, y no de desproporción; y, por otro lado, que su ejecución se haga cumplir sin miramientos ni excepciones. Parece decirnos que «la justicia puede resultar destrozada cuando se opta con exclusividad por alguna clase en detrimento de otra» (Ciuro, 2007, p. 156; las cursivas provienen del original). Agreguemos un detalle significativo que muestra relación con el contexto que refiere la tradición, fines del siglo XVIII, y el contexto desde donde escribe Palma, fines del siglo XIX. Nos atrevemos a conectar los dos contextos toda vez que para Palma en ambos escenarios persiste 
la deficiencia de funcionalidad, que advierte y critica, y que imposibilita la igualdad ante la ley. Esta intuición la apoyamos en las constantes expresiones de desazón política que deja traslucir en sus epístolas. Escribe Palma (2005), el 29 de agosto de 1876: «Abrumado por las decepciones, hace cuatro años que vivo apartado de la política militante de mi tierra» (p. 131). Así, su reflexión sobre la justicia trasciende el marco histórico colonial para posicionarse como idea cuyo alcance abarca el horizonte decimonónico:

la noción de igualdad jurídica presente en el marco legal-institucional y en el discurso oficial del Perú republicano se impuso sobre una sociedad en la que persistían estructuras corporativas que bloquearon la universalización del principio de igualdad. En estas circunstancias, el «imperio de la ley» solo reguló la vida social en algunos espacios limitados como las ciudades, donde los poderes tradicionales se habían erosionado, aunque, incluso en medios urbanos, la resistencia de la élite contra los valores republicanos fue muy intensa (Zapata y Rojas, 2013, pp. 10-11; las cursivas son nuestras).

\section{3. «EL CORREGIDOR DE TINTA»: LA DESMESURA Y EL EQUILIBRIO DE LA JUSTICIA}

La tradición comentada en el apartado anterior coloca frente a nosotros una importante reflexión en torno a la necesidad de comprender que la normativa social de carácter jurídico debe estar guiada por principios de equilibrio o proporcionalidad. Acaso haciéndose eco de la idea platónica de que la injusticia, la desmesura y la falta de razón nos destruyen, y los que nos salvan son la justicia, la templanza, la prudencia y el equilibrio (Pardo, 1983, p. 86). La tradición «El corregidor de Tinta» ofrece al lector un complemento reflexivo respecto de esta idea matriz sobre la justicia como crítica de la desmesura y la búsqueda del equilibrio. Se trata de una tradición que también forma parte de la segunda serie. En esta, Palma 
opta por dejar de lado al cuadro urbano costumbrista para establecer el dominio de su escritura en Tungasuca, Cusco, a 3500 metros sobre el nivel del mar. No debe sorprendernos este desplazamiento, pues el escenario de las tradiciones es múltiple:

Las tradiciones abarcan el más amplio registro histórico que se haya dado en la literatura peruana: desde los Incas hasta mediados del siglo XIX. Y en el espacio llevan al lector desde la capital y las ciudades cálidas de la costa hasta la sierra escabrosa (Oviedo, 1965, p. 173).

En efecto, la clásica anotación histórica que Palma emplea en sus tradiciones sirve esta vez para precisar las coordenadas espaciotemporales donde se insertan los actores y la trama sobre la cual girará la tradición. Así, se describe lo siguiente:

Era el 4 de noviembre de 1780, y el cura de Tungasuca, para celebrar a su santo patrón, que lo era también de su majestad Carlos III, tenía congregados en opíparo almuerzo a los más notables vecinos de la parroquia y algunos amigos de los pueblos inmediatos que, desde el amanecer, habían llegado a felicitarlo por su cumpleaños.

El cura don Carlos Rodríguez era un clérigo campechano, caritativo y poco exigente en el cobro de los diezmos y demás provechos parroquiales, cualidades apostólicas que lo hacían el ídolo de sus feligreses. Ocupaba aquella mañana la cabecera de la mesa, teniendo a su izquierda a un descendiente de los Incas, llamado don José Gabriel Túpac Amaru, y a su derecha a doña Micaela Bastidas, esposa del cacique. Las libaciones se multiplicaban y, como consecuencia de ellas, reinaba la más expansiva alegría. De pronto sintiose el galope de un caballo que se detuvo a la puerta de la casa parroquial, y el jinete, sin descalzarse las espuelas, penetró en la sala del festín.

El nuevo personaje llamábase don Antonio de Arriaga, corregidor de la provincia de Tinta, hidalgo español muy engreído con lo rancio de su nobleza, y que despotizaba, por plebeyos, a europeos $y$ criollos. Grosero en sus palabras, brusco de modales, cruel para 
con los indios de la mita y avaro hasta el extremo de que, si en vez de nacer hombre hubiera nacido reloj, por no dar, no habría dado ni las horas, tal era su señoría. Y para colmo de desprestigio, el provisor y canónigo del Cuzco lo había excomulgado solemnemente por ciertos avances contra la autoridad eclesiástica (Palma, 2014, pp. 201-202; las cursivas son nuestras).

La presentación panorámica de esta tradición nos muestra una nutrida variedad de personajes que pertenecen a grupos sociales distintos: desde el clérigo bonachón e indulgente con los impuestos hasta el corregidor implacable, pasando por un escenario donde figuran también indígenas y notables, entre ellos, el cacique Túpac Amaru y su esposa Micaela Bastidas. La pluma de Palma captura gráficamente el instante. Pero él no quiere proponernos solo una postal perceptiva para contemplar esta diversidad social, sino que la dispone de esa manera para construir una oposición, si se quiere, de administración política equilibrada y convivencia. Notemos que al inicio del texto reina la armonía, tal vez como ejemplo del buen vivir y la política de comunidad, mientras que la llegada del corregidor desencadena conflicto y violencia. Debe tenerse en cuenta la manera como aparece la figura de este personaje, dínamo de violencia y figura de la desmesura. En principio, la tradición lo presenta, antes que con un nombre propio, con un distintivo amenazador: las espuelas que lleva en el calzado ( «sin descalzarse las espuelas, penetró en la sala del festín»).

Los calificativos de corte ético y administrativo que se registran sobre este funcionario real no son exageraciones irónicas. Confirman, más bien, uno de los juicios más extendidos sobre el corregidor: su figura era la más antagónica del sistema colonial, tanto así que las agresiones indígenas, muchas de ellas empujadas hasta la criminalidad, se orientaron hacia él porque abusaba del cobro del tributo y la asignación de la mita. Según los datos que provee la historia, «entre 1770 y 1780, en las provincias de Pacajes, Huamalíes, 
Chumbivilcas, Tinta, Paria, se asesinó a corregidores. La legitimidad de la autoridad de los corregidores estaba en franca crisis» (O'Phelan, 2005, p. 132). No ocurre de otra manera con Arriaga, el corregidor que aparece en la tradición de Palma, pues es calificado como «cruel» y «avaro». Estas actitudes negativas que perturban la cohesión social e instauran el desequilibrio motivarán que se le tome prisionero, juzgue y sentencie no precisamente frente a un virrey, oidor o juez, sino frente a una especie de tribunal de justicia indígena encabezado por el cacique Túpac Amaru, quien resuelve condenarlo a la horca. Leamos la escena completa:

-Dese preso vuesa merced - le dijo Túpac Amaru, que era el que acaudillaba el grupo. Y sin dar tiempo al maltrecho corregidor para que opusiera la menor resistencia, le remacharon un par de grillos y lo condujeron a Tungasuca. Inmediatamente salieron indios con pliegos para el Alto Perú y otros lugares, y Túpac Amaru alzó bandera contra España. Pocos días después, el 10 de noviembre, destacábase una horca frente a la capilla de Tungasuca; y el altivo español, vestido de uniforme y acompañado de un sacerdote que lo exhortaba a morir cristianamente, oyó al pregonero estas palabras:

Esta es la justicia que don José Gabriel I, por la gracia de Dios, Inca, rey del Perú, Santa Fe, Quito, Chile, Buenos Aires y continente de los mares del Sur, duque y señor de los Amazonas y del gran Paititi, manda hacer en la persona de Antonio de Arriaga por tirano, alevoso, enemigo de Dios y sus ministros, corruptor y falsario.

Enseguida, el verdugo, que era un negro esclavo del infeliz corregidor, le arrancó el uniforme en señal de degradación, le vistió una mortaja y le puso la soga al cuello. Mas al suspender el cuerpo, a pocas pulgadas de la tierra, reventó la cuerda, y Arriaga, aprovechando la natural sorpresa que en los indios produjo este incidente, echó a correr en dirección a la capilla, gritando: «iSalvo soy! ¡A iglesia me llamo! ¡La iglesia me vale!».

Iba ya el hidalgo a penetrar en sagrado, cuando se le interpuso el Inca Túpac Amaru y lo tomó del cuello, diciéndole:

- ¡No vale la iglesia a tan gran pícaro como vos! ¡No vale la iglesia a un excomulgado por la Iglesia! 
Y volviendo el verdugo a apoderarse del sentenciado, dio pronto remate a su sangrienta misión (Palma, 2014, pp. 203-204; las cursivas provienen del original).

A postrimerías de conmemorar el Bicentenario de nuestra Independencia, el pasaje antes citado nos recuerda uno de los momentos capitales de las rebeliones indígenas que antecedieron a la gesta independentista: el levantamiento indígena protagonizado por José Gabriel Túpac Amaru, quien, cansado del abuso de la administración colonial y tras no ser escuchado en sus demandas, buscó libertad y justicia para su pueblo. Los cargos que se le atribuyen al corregidor son expresivos de su nociva personalidad para la pacífica vida en comunidad: él es «tirano, alevoso, enemigo de Dios y sus ministros, corruptor y falsario» (Palma, 2014, p. 204). Se puede entender que tanto en esta como en la anterior, las tradiciones contienen significativas reflexiones sobre las fórmulas jurídicas que se adoptan para la vida en sociedad. Por un lado, para frenar los actos delictivos y criminales, se promulgan los bandos que condenan con privación de la libertad a los infractores (pero también con la muerte); y, por el otro, desde la condición de autoridad espiritual y territorial de raza, se usa la condena a la horca para ajusticiar a las autoridades del opresivo sistema de administración colonial.

Esta última escena del ahorcamiento no es minuciosa; sin embargo, lo que se detalla es suficiente para entender lo vejatorio que resultaba para un funcionario de la Corona verse sometido a la horca, no solo porque se trataba de una condena destinada exclusivamente a plebeyos, sino porque era ejecutada por un grupo de indígenas, aunque entre ellos se encontraba el cacique. Mucho más si, como refiere el tradicionista, el «verdugo» encargado «era un negro esclavo del infeliz corregidor», quien «le arrancó el uniforme en señal de degradación, le vistió una mortaja y le puso la soga al cuello» (Palma, 2014, p. 204). No debe sorprendernos la condena a la horca, pues, según el derecho penal de la época, «el uso de este sistema de 
ejecución llegó a ser tan habitual durante los siglos XVI, XVII y XVIII, que las sentencias dictadas establecían tan solo pena de "muerte ordinaria" o en la "forma ordinaria", entendiéndose que esta era la horca» (Tomás y Valiente, 1969, pp. 383-384). Es cierto que en las tradiciones de Palma no encontraremos demasiados detalles sobre el ajusticiamiento por horca (la notificación de la sentencia, el ritual de preparación y los instrumentos usados); no obstante, cuando estas brutales escenas aparecen, el tradicionista nos hace partícipes de sus reflexiones sobre los usos y abusos. Con ello, además, devela los dispositivos con los que el sistema de administración colonial producía crueldad y temor. La tradición confirma así que «el régimen colonial estaba fundado sobre la violencia y sostenido por la tiranía» (Brading, 1991, p. 441).

Hasta este punto, la tradición de Palma parece avanzar hacia la presentación de los efectos que produjo el revolucionario ajusticiamiento por horca. ¿Y cuáles son esos efectos? El tradicionista apunta que tras la captura y la muerte del corregidor Arriaga,

el 6 de abril, Viernes de Dolores del año 1781, cayeron prisioneros el Inca y sus principales vasallos, con los que se ejercieron los más bárbaros horrores. Hubo lenguas y manos cortadas, cuerpos descuartizados, horca y garrote vil. Areche autorizó barbaridad y media (Palma, 2014, p. 206; las cursivas son nuestras).

La brevedad del fragmento sintetiza la intensidad de los hechos. Es como si frente a tamaña atrocidad, desbordante y desmesurada, el discurso del tradicionista se entrecortara hasta no poder relatar más. Incluso, si nos fijamos, y si hacemos un ejercicio de imaginación reconstructiva, el discurso no otorga lugar para señalar que hay, sin duda, charcos y charcos de sangre. Y es que tras el cuerpo descuartizado, las lenguas y las manos trozadas, se deja ver la maximización de la violencia. La condena a muerte para los rebeldes no es suficiente. Lo realizado por el visitador Areche añade suplicios 
y tormentos para prolongar el sufrimiento y producir temor en los espectadores. De hecho, para la época, la ejecución por horca «consistía en que los ajusticiados podían ser colgados por los pies, brazos, axilas u órganos genitales» (Sueiro, 1974, pp. 69-70). No obstante, el tormento añadía a la condena algunos elementos para potenciar el sufrimiento, como «cuando el reo era colgado de los pies y se le ponían brasas debajo, o animales como perros, lobos o cerdos, para que les comiesen la cabeza y el tronco» (Sueiro, 1974, p. 263). Es decir, a la condena de horca «podía acompañar el descuartizamiento, pudiendo ser el penado bajado de la cuerda aún con vida para proceder con su descuartizamiento» (Sueiro, 1974, pp. 69-70).

La tradición nos ha puesto frente a dos hechos de muerte. ¿Acaso para que la contemplemos solamente? ¿O para que juzguemos cuál resulta más brutal, si lo realizado por José Gabriel Túpac Amaru o lo resuelto por Areche? La posición de Palma frente a la muerte por descuartizamiento es clara. El calificativo «bárbaros horrores» expresa su rechazo y desacuerdo, pues los actos exceden la búsqueda de justicia y colindan más con la práctica de la violencia pura y con el exhibicionismo de la fuerza salvaje usada para amedrentar a los posibles indígenas rebeldes. Nos convence esta idea, que se enriquece con otra presentada para agregar elementos reflexivos sobre la justicia: al final de la tradición se cuenta de qué forma vengaron los indios la muerte de su inca, sin derramar sangre ni cebarse sobre el cuerpo del ajusticiado. ¿Y cómo? Leamos:

Es fama que el 26 de abril de 1784 el virrey don Agustín de Jáuregui recibió el regalo de un canastillo de cerezas, fruta a la que era su excelencia muy aficionado, y que apenas hubo comido dos o tres cayó al suelo sin sentido. Treinta horas después se abría en Palacio la gran puerta del salón de recepciones; y en un sillón bajo el dosel se veía a Jáuregui vestido de gran uniforme. Con arreglo al ceremonial del caso, el escribano de cámara, seguido de la Real 
Audiencia, avanzó hasta pocos pasos del dosel, y dijo en voz alta por tres veces: «¡Excelentísimo señor don Agustín de Jáuregui!». Y luego, volviéndose al concurso, pronunció esta frase obligada: «Señores, no responde. ¡Falleció! ¡Falleció! ¡Falleció!». En seguida sacó un protocolo, y los oidores estamparon en él sus firmas. Así vengaron los indios la muerte de Túpac Amaru (Palma, 2014, p. 206; las cursivas son nuestras).

El detalle es significativo. El tradicionista nos ha conducido paso a paso a que, como lectores, activemos nuestros mecanismos de identificación con los protagonistas. Hasta este punto se han desencadenado los sentimientos de rechazo hacia uno y aceptación empática con otros. Y resulta evidente hacia qué lado de la balanza se inclina Palma. Vemos que la tradición no ofrece una censura sobre la muerte del corregidor Antonio de Arriaga. Sí, en cambio, sobre el ajusticiamiento de los sublevados indígenas. Estas visibles posturas a favor de uno y en contra del otro sugieren con total claridad la idea de justicia que se desprende de esta tradición. En efecto, Palma advierte que el problema indígena es un asunto de lucha por la justicia y la libertad. Y nos hace contemplar la crueldad y brutalidad que produce la legislación virreinal de la mano con la violencia y el sadismo más espantoso (véase Neuman, 2004, p. 28). A partir de ello, podemos inferir que se retoman los asuntos históricos resueltos injustamente para que en la composición y la escritura de esta tradición se resuelvan con justicia. Los ecos ideológicos de su postura «romántic[a] liberal» son evidentes (Pérez, 2015). De hecho, este es el modo como, desde la imaginación narrativa de la tradición, híbrido de fábula e historia, se despierta el interés por el bienestar de los demás, y en este momento auroral donde la solidaridad se combina con diversas reflexiones y emociones, el discurso literario de Palma busca lo que bien llamó Martha Nussbaum «justicia poética». 


\section{LA FALACIA AD HOMINEM EN «JUSTOS Y PECADORES»}

Pero no siempre estos textos palmistas nos presentan aquella imagen y postura sobre el ajusticiamiento por horca. La tradición «Justos y pecadores» ofrece una reflexión sobre lo negativas que resultan las impresiones y las apariencias en materia de juicio y condena de presuntos responsables de las acciones en contra de la paz y el bienestar social. Esta tradición narra la historia de un crimen por venganza: Juan de Toledo asesina por la espalda al capitán Martín de Salazar, el prometido de su hermana Engracia, porque este se niega a cumplir con su promesa de matrimonio, pues está en amoríos con otra muchacha llamada Transverberación, sobrina del barbero y tabernero apodado Ibirijuitanga. Los hechos son descritos de manera que el lector tenga la certeza de que el criminal es Juan de Toledo y no otro. Es más, el tradicionista registra el preciso momento en que Engracia, poseída por la cólera e indignación de saberse rechazada, le solicita a su hermano la vida de su deshonrador: "¿por qué no lo heriste sin compasión? ¿Por qué no le diste muerte de traidor? ¡Mátale, hermano! ¡Mátale!» (Palma, 2014, p. 123). Y renglones más adelante veremos al personaje con el rostro cubierto y al amparo del crepúsculo; su víctima no lo ve, y por la espalda, puñal en mano, resuelve con frialdad, celeridad y contundencia al pedido de su hermana.

Palma no quiere mostrar a un personaje que delibera sobre si resulta correcto o no dar muerte a quien acaba de faltar al compromiso de casarse con su hermana. Y no es el propósito del tradicionista, pues quiere conducir el relato de la historia hacia el tópico de juzgar y condenar sin pruebas a dos inocentes. De este modo, la tradición instala el problema de dar la muerte, en el corazón mismo de la administración de justicia. ¿Y para qué realiza esta operación de la imaginación narrativa? Justamente para llamar la atención sobre la necesidad de mejorar la capacidad técnico-reflexiva y afectiva de los responsables de administrar la justicia, es decir, de 
aquellos funcionarios que tienen en sus manos el derecho de matar. El contexto en el que se desarrolla la tradición nos precisa que estamos lejos de que se introduzca en ella la abolición de la pena de muerte por horca, y que se sustituya por la pena de muerte por fusilamiento. Recordemos que este cambio de naturaleza jurídica recién comenzará a implementarse en el Perú tras la proclamación del decreto del 3 de enero de 1822, fecha en la cual el Libertador, general don José de San Martín, dejara por escrito que «queda abolida en el Perú la pena de horca, y los desgraciados contra quienes pronuncie la justicia el fallo terrible serán fusilados indistintamente» (citado por Odriozola, 1872, p. 398). No estamos en este contexto de génesis republicana, pero precisamente para reflexionar sobre la necesidad de perfeccionar la justeza de la pena por horca es que Palma escenifica el caso y presenta para tal efecto a todos los representantes del sistema de administración judicial colonial. Cual estampa fotográfica desfilan en la tradición representantes de la Real Audiencia, el alcalde, los alguaciles y los oidores, en una muestra clara de permeabilidad de poderes al momento de impartir justicia (Ramos, 2019, pp. 35-38). Todos están irrefutablemente convencidos de la culpabilidad del barbero y su sobrina. Leamos el extenso pasaje donde se escenifica el ajusticiamiento por horca:

Quince días más tarde se elevaba una horca en la plaza de Lima. La Real Audiencia no se había andado con pies de plomo, y a guisa de aquel alcalde de casa y corte que previno a sus alguaciles que, cuando no pudiesen haber a mano al delincuente, metiesen en chirona al primer prójimo que encontrasen por el camino, había condenado a hacer zapatetas en el aire al desdichado barbero. Para los jueces el negocio estaba tan claro que más no podía serlo. [...] Atemos cabos, se dijeron los oidores, y tejamos cáñamo para la horca, pues importa un ardite que el redomado y socarrón barbero permanezca reacio en negar, aun en el tormento, su participación en el crimen.

[...] 
Los incidentes del proceso eran la comidilla obligada de las tertulias. Las mujeres pedían un encierro perpetuo para la escandalosa sobrina, y los hombres la horca para el taimado barbero.

La Audiencia dijo entonces: «Serán usarcedes servidos»; y aunque Ibirijuitanga puso el grito en el cielo, protestando su inocencia, le contestó el verdugo: «¡Calle el vocinglero y déjese despabilar!».

$[\ldots]$

- iJusticia de los hombres! ¡No en vano te pintan ciega! (Palma, 2014, pp. 118-119; las cursivas son nuestras).

Palma nos tiene acostumbrados a este cuadro vivo de personajes. El pasaje citado condensa una serie de sucesos que acompañan la determinación de los operadores de justicia. El tradicionista enfatiza que, tanto para los ciudadanos como para las autoridades, el acusado, un hombre que regenta la barbería y bodega, es un personaje cuyas maneras poco amigables revelarían su propensión a cometer cualquier delito; y su sobrina, de carácter extrovertido, también estaría llamada a delinquir. En este punto donde la descripción de los personajes se mueve como si se tratara de la elaboración de un perfil de conducta propenso a la criminalidad, resulta imposible no asociarlo con las caracterizaciones deterministas que realiza el criminólogo César Lombroso (1894) a propósito de la formación del homo criminalis. Sin embargo, más que ilustrar la severidad y la irrevocabilidad de la pena, la tradición pretende dar a entender que aquellos dos inocentes fueron sentenciados sin pruebas concretas ni contundentes, dado que solo se señalan estos argumentos ad hominem, fundados en especulaciones y comentarios sobre sus personalidades. Recordemos que las falacias ad hominem son «argumentos que pretenden descalificar a alguien en razón de su ideología, clase social, nacionalidad, antecedentes, costumbres» (Fernández, 2011, p. 68).

Cuando Palma presenta en sus tradiciones este tipo de sucesos injustos, no se contenta con mostrarle al lector cómo se origina y 
cómo concluye el caso: le interesa reflexionar sobre el proceso de injusticia, y para hacerlo, introduce detalles que agregan descontento y rechazo por la injusta pena. Se trata de una lógica reflexiva que también se plasma en esta tradición. Por ello, al final, y después de que el lector probablemente se haya condolido por el trágico destino de los inocentes, se inserta un detalle que acrecienta el descontento sobre el final del tío y la sobrina. Se presenta en la tradición la confesión del verdadero asesino del capitán Martín de Salazar. El criminal, próximo a morir, escribe sus últimas palabras:

Yo, don Juan de Toledo, a quien todos hubisteis por santo, y que usé hábito penitencial, no por virtud, sino por dañada malicia, declaro en la hora suprema: que habrá poco menos de veinte años que, por agravios que me hizo don Martín de Salazar en menoscabo de la honra que Dios me dio, le quité la vida a traición, y después que lo enterraron tuve medios de abrir su sepultura, comer a bocados su corazón, cortarle la cabeza, y habiéndole vuelto a enterrar me llevé su calavera, con la que he andado sin apartarla de mi presencia, en recuerdo de mi venganza y de mi agravio. ¡Así Dios le haya perdonado y perdonarme quiera! (Palma, 2014, pp. 122-123; las cursivas son nuestras).

Haber dispuesto para el final este importante hecho no solo muestra la capacidad estructurante de Palma, quien al proceder de este modo genera expectativa en el lector, sino que expresa también su intención de hacer visible la equivocación de la condena. La imaginación narrativa que ofrece la tradición avanza hasta el punto donde el relato de los hechos funciona como medio que repara la memoria de los injustamente condenados. Nos atreveríamos a señalar que es un modo de producir «justicia literaria», una suerte de experiencia que el lector experimenta al ver plasmarse la justicia (véase Nussbaum, 2005, p. 102). El conjunto de elementos de reflexión jurídica que provee esta tradición es amplio y merece un examen detenido. Lo que buscamos destacar es que, para Palma, 
la administración de justicia no debiera impartirse recurriendo a argumentos ad hominem, dado que la apariencia del imputado, o lo que se presuma de él (costumbres y actitudes), no resuelven el caso. La acusación y la condena deberían realizarse - reitera-con pruebas que demuestren efectivamente la culpabilidad o la autoría del delito. Y si queda duda de ello, la tradición culmina con esta escena donde participan sujetos versados en leyes y derecho, ni más ni menos, admitiendo que la apariencia engaña:

Los notarios hicieron añicos el expediente y los que tres minutos antes encontraban olor a rosas en el difunto se esparcieron por la villa, asegurando que el cadáver del de Toledo estaba putrefacto y nauseabundo, y que no volverían a fiarse de las apariencias (Palma, 2014, p. 123; las cursivas son nuestras).

La insistencia por mostrar los argumentos ad hominem en las conjeturas del pueblo para exigir justicia parece un problema que algunas tradiciones palmistas evalúan para aconsejar que la administración judicial no debe aceptar ese tipo de falacias en ningún caso.

Estas tres tradiciones presentan las reflexiones de Palma sobre el fracaso de la administración de justicia virreinal. En el primer caso, por una sistemática falta en el cumplimiento de funciones y por falta de horizontalidad en la aplicación de la normativa legal. El segundo, más bien, representa el caso donde la combinación de administración de justicia y violencia desmedida produce acontecimientos bárbaros y monstruosos. Y en el tercer caso se presenta a los administradores de justicia condenando a muerte a un inocente. Estas tradiciones ambientadas en el siglo XVIII parecen decirnos que cuando se trata de reflexionar sobre la administración de justicia virreinal, existen más yerros que aciertos. La idea se redondea si tomamos en cuenta que el tradicionista escribe sus tradiciones en el siglo XIX. La lección que realiza Palma cae por su propio peso: 
comprender los yerros del pasado para no repetirlos en el presente ni heredarlos para el mañana. El insumo reflexivo sobre la cultura jurídica de la literatura lo hemos reformulado de la expresión «la cultura literaria del derecho» del fallecido jurista y filósofo sevillano José Calvo González (1956-2020). El tradicionista, pretendiéndolo o no, muestra, desde el espacio literario, por dónde debe comenzar el trabajo de reformar la justicia. El puente que comunica el derecho y la literatura se hace visible y necesario de transitar. Una provee historias, anécdotas y personajes inmersos en situaciones que los conducen por la movediza arena de la administración de la justicia. En las tradiciones vemos no solo a virreyes, oidores, escribanos, jueces, abogados, miembros de la Real Audiencia, condes, militares, alguaciles y alcaldes, sino también a los litigantes que exigen justicia. Esto es, un significativo grupo de hombres de letras y ciencias, religiosos e incas de la nobleza $y$, asimismo, personajes que provienen de diferentes grupos sociales de la época, como los indígenas. Los casos que estos personajes escenifican y la manera de resolverlos en las tradiciones cumplen un rol importante, pues acrecientan la imaginación del quehacer de la justicia.

\section{REFERENCIAS}

Ávila, A. de (1946). Aspectos del derecho penal indiano. Instituto de Historia del Derecho.

Brading, D. A. (1991). Orbe indiano. De la monarquía católica a la república criolla, 1492-1867. Fondo de Cultura Económica.

Castro, I. (2016). Ordenar el universo de los signos. Bandos, pregones y espacio urbano en España y América durante la Edad Moderna. LaborHistórico, 2(1), 16-29. https://revistas.ufrj.br/ index.php/lh/article/view/4805/3513 
Ciuro, M. Á. (2007). Ubicación de la justicia en el mundo del valor (el asalto al valor justicia). Estudios de Filosofía Jurídica y Filosofía Política, 2, 149-160. http://www.cartapacio.edu.ar/ojs/ index.php/iyd/article/viewFile/934/770

Cornejo, J. (1998). Estudios de literatura peruana. Universidad de Lima; Banco Central de Reserva del Perú.

Fernández, G. (2011). Argumentación y lenguaje jurídico. Aplicación al análisis de una sentencia de la Suprema Corte de Justicia de la Nación. Universidad Nacional Autónoma de México.

Lombroso, C. (1894). Los criminales. La Presa.

Neuman, E. (2004). Pena de muerte. La crueldad legislada. Universidad.

Nussbaum, M. C. (2005). El conocimiento del amor. Ensayos sobre filosofía y literatura. Antonio Machado Libros.

Odriozola, M. de (1872). Documentos históricos del Perú. Tomo 3. Imprenta del Estado.

O'Phelan, S. (2005). La construcción del miedo a la plebe en el siglo XVIII a través de las rebeliones sociales. En Rosas, C. (ed.), El miedo en el Perú. Siglos XVI al XX (pp. 123-138). Seminario Interdisciplinario de Estudios Andinos; Fondo Editorial de la Pontificia Universidad Católica del Perú.

Oviedo, J. M. (1965). Genio y figura de Ricardo Palma. Editorial Universitaria de Buenos Aires.

Palma, R. (2005). Epistolario general (1846-1891) (M. Á. Rodríguez, ed.). Editorial Universitaria.

Palma, R. (2014). Tradiciones peruanas. Primera y segunda series (M. Á. Rodríguez, ed.). Editorial Universitaria.

Pardo, I. J. (1983). Fuegos bajo el agua: la invención de utopía. Biblioteca Ayacucho. 
Pásara, L. (1982). Jueces, justicia y poder en el Perú. Centro de Estudios de Derecho y Sociedad.

Pérez, C. (2015). Liberalismo criollo. Ricardo Palma, ideología y política (1848-1919). Editorial Universitaria.

Ramos, C. (2019). Historia de la Corte Suprema de Justicia del Perú.

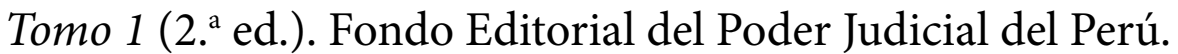

Sueiro, D. (1974). La pena de muerte: ceremonial, historia, procedimientos. Alianza.

Tomás y Valiente, F. (1969). El derecho penal de la monarquía absoluta (siglos XVI-XVIII-XVIII). Tecnos.

Trazegnies, F. de (2011). La interacción entre Literatura y Derecho. En Trazegnies, F. y Gatti, C., Derecho y Literatura (pp. 17-31). Universidad del Pacífico.

Zapata, A. y Rojas, R. (2013). ¿Desigualdades de siempre? Miradas históricas sobre la desigualdad. Instituto de Estudios Peruanos. 